\title{
Sella turcica variations in lateral cephalometric radiographs and their association with malocclusions
}

\author{
Hale Öktem ${ }^{1}$, N. İrem Tuncer ${ }^{2}$, Tuğçe Şençelikel ${ }^{3}$, Z. İlayda Bağcr ${ }^{4}$, Sude Cesaretli ${ }^{4}$, Almina Arslan ${ }^{4}$, \\ Ilgaz Tuana Gürsel ${ }^{4}$, Bengisu Değirmenci ${ }^{4}$ \\ ${ }^{1}$ Department of Anatomy, Faculty of Medicine, Baskent University, Ankara, Turkey \\ ${ }^{2}$ Department of Orthodontics, Faculty of Dentistry, Baskent University, Ankara, Turkey \\ ${ }^{3}$ Department of Biostatistics, Faculty of Medicine, Baskent University, Ankara, Turkey \\ ${ }^{4}$ Term-III Student, Faculty of Medicine, Basskent University, Ankara, Turkey
}

\begin{abstract}
Objectives: Classification of the skeletal facial types is performed using certain reference points and planes in lateral cephalometric radiographs to plan orthodontic treatments. One of these reference points is sella turcica which is closely associated with craniofacial bone development. The aim of this study was to identify the association between the sella turcica variations and skeletal Class I, II, and III malocclusions.

Methods: This study retrospectively evaluated 94 orthodontic patients (48 males and 46 females) between 14-26 years of age. Lateral cephalometric radiographs of the patients with skeletal Class I, II, and III malocclusions were classified into six groups according to sella turcica morphology: normal sella turcica, oblique anterior wall, double contour of the floor, sella turcica bridge, irregularity in the posterior part, and pyramidal shape of sella turcica. The length, depth, and diameter of sella turcica were measured. Sella turcica variations and radiographs of patients with Class I, II, and III malocclusions were compared statistically.

Results: The correlation between the sella turcica variations and skeletal sagittal classification was statistically significant ( $p=0.017$ ). $36.8 \%$ of the radiographs, which were classified as normal sella turcica were classified as Class I patients. There were no statistically significant differences between the skeletal Class I, II, and III malocclusions and sella turcica variations in terms of the length, depth, and diameter.

Conclusion: For adequate patient referral and management, orthodontists should recognize sella turcica variations in lateral cephalometric radiographs, and these findings should arise an index of suspicion for associated pathologies, especially of the hypophyseal gland.
\end{abstract}

Keywords: sella turcica; lateral cephalometric radiography; malocclusion; skeletal class I, II, III

Anatomy 2018;12(1):13-19 @2018 Turkish Society of Anatomy and Clinical Anatomy (TSACA)

\section{Introduction}

The sphenoid bone which is located in the middle of the skull base articulates with most of the bones forming the skull. The so-called corpus sphenoidale is the body of sphenoid bone. The concavity in the middle part of the upper surface of corpus sphenoidale is the hypophyseal fossa, in which the hypophysis lies. ${ }^{[1,2]}$
The hypophyseal fossa is limited by the tuberculum sellae anteriorly and dorsum sellae posteriorly. The two small processes on both sides of the tuberculum sellae are named as middle clinoid processes and the small processes on the superior lateral corners of the dorsum sellae are the posterior clinoid processes. The hypophyseal fossa is examined in three parts, namely, the anterior wall, poste-

This study was presented at Anatomi Kı̧̧ Günleri 2018, 25-28 January, Kızllcabamam, Ankara, Turkey. 
rior wall, and the floor. Because these three structures resemble a Turkish saddle, this region is named as sella turcica ${ }^{[1-6]}$ Development of sella turcica is closely associated with the development of the hypophysis. The size of the sella turcica will vary depending on the normal or pathological development of the hypophysis, ${ }^{[3,4]}$ which is the primary endocrine gland controlling most of the endocrine functions. $25 \%$ of the anomalies diagnosed in the lateral cephalometric radiograms by the orthodontists account for the glandular anomalies. The most common radiologic manifestation of these anomalies is enlarged sella turcica due to a hypophyseal adenoma. ${ }^{[2,7]}$ Besides its importance endocrinologically, the hypophysis is also important due to its anatomical location, including its proximity to the hypothalamus, optic chiasm, sphenoid sinus, cavernous sinus and its internal anatomic structures. ${ }^{[4,5]}$ The recent developments in endoscopy allowed transnasal endoscopic approaches performed in the sellar region and its surroundings. The anatomical structures, especially the shape of the posterior clinoid processes, are of importance during this process. As the advanced radiological investigations are required for three-dimensional evaluations of the anatomic structures in the pre-operative period, identifying the presence of any variations of sella turcica in the lateral cephalometric radiographs may be beneficial as a preliminary information, providing a guide for the patient management. ${ }^{[8]}$

Embryological development of sella turcica is associated with the development of craniofacial bones with its anterior part developing from the neural crest cells, and its posterior part developing from the paraxial mesodermal cells. Sella turcica plays a key role in the migration of neural crest cells towards the frontonasal and maxillary areas under embryologic development. While the anterior wall anomalies of the sella turcica are associated with the anomalies in the frontonasal region, the ones belonging to the posterior wall are associated with the cerebral developmental defects. ${ }^{[2]}$ Studies in monozygotic twins have shown that genetic factors are not solely responsible for the genesis of the sella turcica morphology. ${ }^{[9]}$

Certain reference points and planes are used as landmarks in lateral cephalometric radiographs for sagittal classification of facial types and for the planning of orthodontic treatments. In this aspect, sella is important because of its central location as a reference point in cranial morphology and its relation with the intermaxillary suture. ${ }^{[2,3,7]}$ Therefore, the S point, where the sella turcica is located, bears importance for the practice of orthodontists. On the other hand, the anterior wall structure is more reliable in cases when variations of the sella turcica are present. ${ }^{[10]}$
One of the measurements, which shows the sagittal relation between maxilla and mandibula is the 'ANB' angle. This angle is formed by the arbitrarily named points $\mathrm{A}, \mathrm{N}$, and $\mathrm{B}$ defining the cephalometric landmarks as follows: First, point $\mathrm{A}$ is the deepest point in the bony concavity, extending from the anterior nasal spine to the first upper incisor. Secondly, the point N (nasion) is the union point of the frontal and nasal bones. And finally, the third one, point $B$ is the deepest point of the mandibular concavity extending from the lower incisors of mandibula to the tip of the chin (Figure 1).

The size and shape of the sella turcica may be variable ranging from 4 to $12 \mathrm{~mm}$ vertically and from 5 to $16 \mathrm{~mm}$ anteroposteriorly in size. ${ }^{[3]}$ Assessment of these variabilities in the size of the sella turcica in terms of malocclusions may be beneficial in planning the treatment.

For the assessment purposes, morphological variations of the sella turcica may be classified under the following headings: normal sella turcica, oblique anterior wall, double contour of the floor, sella turcica bridge, irregularity in the posterior part of the sella turcica, and pyramidal shape of dorsum sella. ${ }^{[1-15]}$

The most common variation of the sella turcica in the orthodontic literature is the sella turcica bridge - the manifestation of the union of the anterior and posterior structures of the sella turcica. The image of this variation may be the display of the calcification of the interclinoid liga-

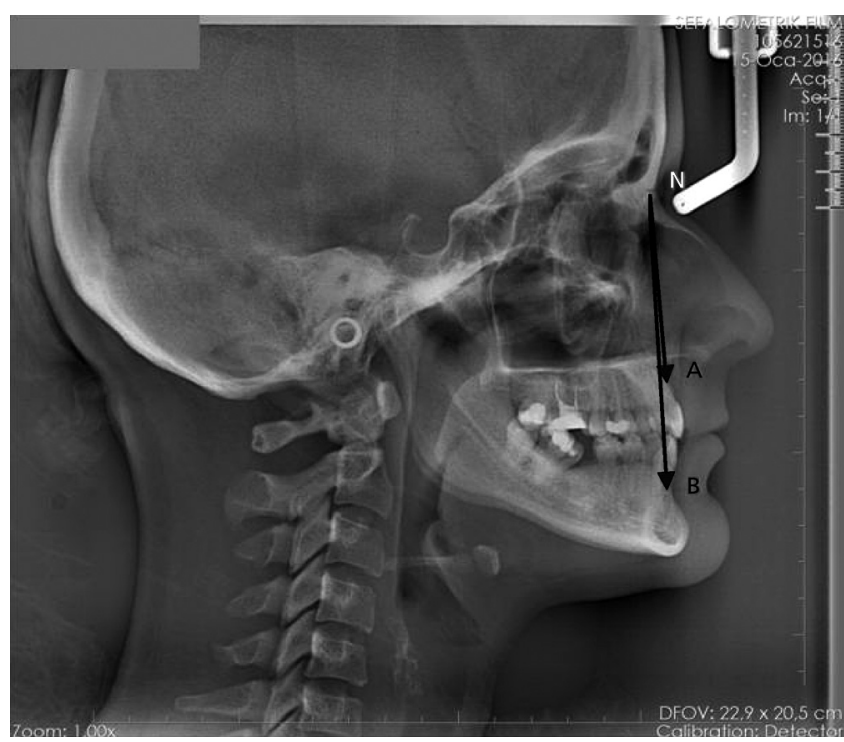

Figure 1. ANB angle. A: deepest point in bony concavity extending from the anterior nasal spine to the first upper incisor; $B$ : deepest point of the mandibular concavity which extends from the lower incisors of mandibula to the tip of the chin; $\mathrm{N}$ : nasion, the union point of frontal and nasal bones. 
ment or it may be formed by the superimposition of the sellar structures. ${ }^{[2]}$ It is reported in the literature that the sella turcica bridge is associated with local dental anomalies. ${ }^{[16]}$

The aim of this study was to define the sella turcica variations and determine the associations of skeletal Class I, II, and III malocclusions to the sella turcica variations.

\section{Materials and Methods}

This study included 94 patients (48 males and 46 females) between 14-26 years of age admitted to Başkent University, School of Dentistry between 2013-2017, whose lateral cephalometric radiographs were obtained by the same imaging device (Veraviewepocs ${ }^{\circledR}$, Morita, CA, USA). The radiographs included in this study were randomly selected from a pool of 3517 patient records. The radiographs were excluded from the study if the following were present including any signs of a syndrome, cleft lippalate, history of a previous maxillofacial surgery or previous orthognathic surgery, or any known endocrine diseases. In addition, the radiographs of patients that went under endocrinologic treatment were excluded. Furthermore, the radiograms with a double view or if the sella turcica could not be visualized clearly were also excluded. The drawings, measurements, and filtrations on the cephalometric radiographs were performed with Dolphin Imaging software (Vers 11.5 Premium, Patterson Dental, St. Paul, MN, USA) using the appropriate criteria.

Skeletal classification of the cephalometric radiographs was made using the ANB angle. Patients with an ANB angle between $0^{\circ}$ to $4^{\circ}$ were accepted as skeletal Class 1 , the patients with an angle above $4^{\circ}$ were accepted as skeletal Class II, and the patients with an angle below $0^{\circ}$ were

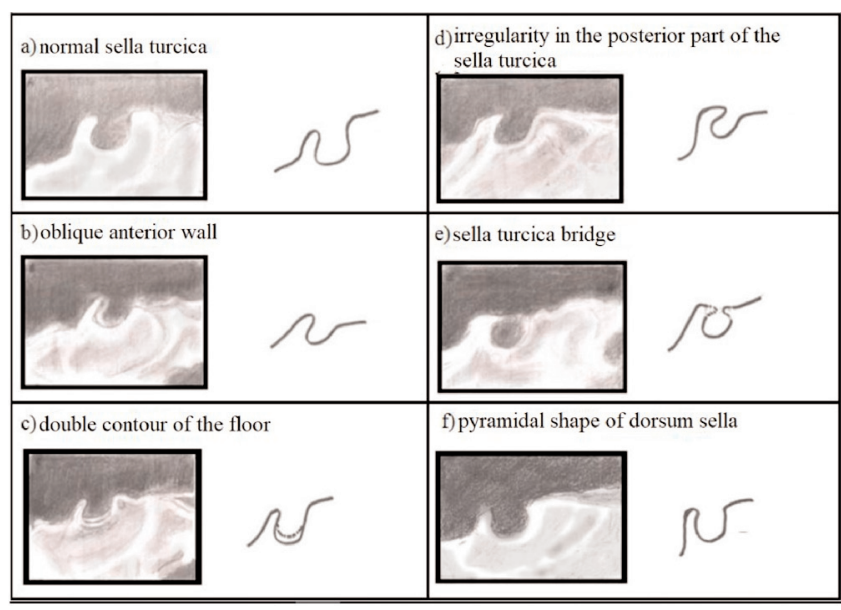

Figure 2. Morphological variations of sella turcica in six groups. accepted as skeletal Class III. The results of the Wits' analysis were evaluated in order to eliminate the possibility of the mandibular posterior rotation obscuring any skeletal anomalies in the patients with increased perpendicular direction values. For this purpose, the radiographs were excluded if the results from the ANB angle measurements and Wits' analysis did not coincide. To eliminate the effects of growth-related changes in the post-pubertal period, the patients, who completed or who were about to complete their growth processes were included in the study. Therefore, the lower limit of the age range of the study patients was determined to be 14 years in females, and 16 years in males. The upper limit of the age range was 26 years.

According to these inclusion and exclusion criteria, 94 individuals were included in the study. Of these, 30 were classified as skeletal Class I, 31 skeletal Class II, and 33 skeletal Class III. The magnification ratio was eliminated by calibration by means of a radioopaque ruler image with a known spatial size, located at the upper right corner of the radiographs.

Radiographs of the patients with skeletal Class I, II, III malocclusions were classified in six groups according to sella turcica variations as follows: a) normal sella turcica, b) oblique anterior wall, c) double contour of the floor, d) irregularity in the posterior part of the sella turcica, e) sella turcica bridge, and f) pyramidal shape of dorsum sella (Figure 2). ${ }^{[4]}$

The measurements of sella turcica were performed on the radiographs. Calculated variables including the length, depth, and diameter values of sella turcica were illustrated in Figure 3. The length was measured as the distance between the tuberculum sellae and dorsum sellae. The

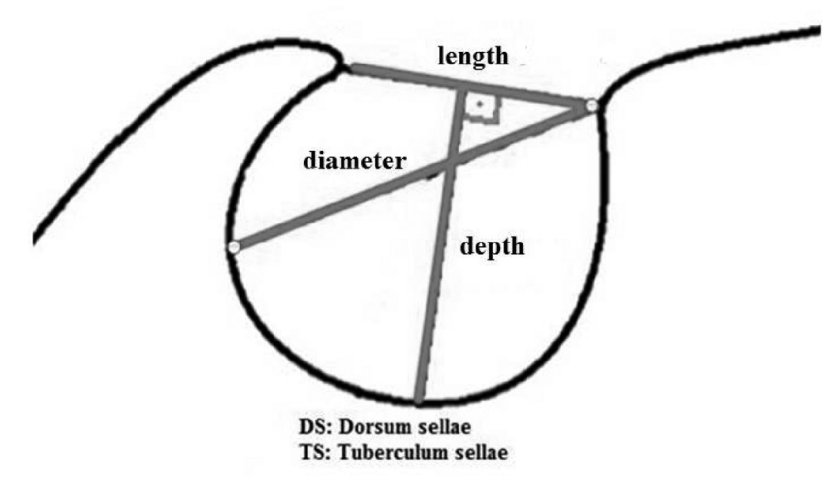

Figure 3. Measurements of sella turcica. 
Table 1

Dependence of Classes I, II, III malocclusions and sella turcica variations.

\begin{tabular}{|c|c|c|c|c|c|}
\hline Sella turcica variants & Class I & Class II & Class III & Total & p \\
\hline Normal & $14(46.7 \%)$ & $10(30.3 \%)$ & $14(45.2 \%)$ & $38(40.4 \%)$ & \multirow{6}{*}{$0.017^{*}$} \\
\hline Oblique anterior wall & $0(0 \%)$ & $3(9.1 \%)$ & $3(9.7)$ & $6(6.4 \%)$ & \\
\hline Double contour of the floor & $7(23.3 \%)$ & $2(6.1 \%)$ & $0(0 \%)$ & $9(9.6 \%)$ & \\
\hline Sella turcica bridge & $3(10 \%)$ & $4(12.1 \%)$ & $0(0 \%)$ & $7(7.4 \%)$ & \\
\hline Irregularity in the posterior part & $4(13.3 \%)$ & $8(24.2 \%)$ & $9(29 \%)$ & $21(22.3 \%)$ & \\
\hline Pyramidal shape of dorsum sellae & $2(6.7 \%)$ & $6(18.2 \%)$ & $5(16.1 \%)$ & $13(13.8 \%)$ & \\
\hline Total & $30(100 \%)$ & $33(100 \%)$ & $31(100 \%)$ & $94(100 \%)$ & \\
\hline
\end{tabular}

*Fisher-Freeman-Halton exact test

depth was measured as the distance extending from the length line to the deepest point of the hypophyseal fossa. And finally, the diameter was measured as the distance between the tuberculum sellae and the most posterior point inside the fossa.

Descriptive statistics were expressed as mean and standard deviation values when the parametric assumptions were satisfied. If these assumptions were not satisfied, the descriptive statistics were expressed as median (minimummaximum) values. The descriptive statistics for the categorical variables were given as frequency (n) and percentage (\%).

To evaluate the intra-rater reliability, 30 radiographs were randomly selected 30 days later than the initial evaluations. Then, the length, depth, and diameter of the sella turcica were measured, determining the variants. To evaluate the correlation between two measurements, the Intraclass Correlation Coefficient (ICC) was calculated. The Kappa coefficient was calculated to test for the agreement of nominal categorical variables between two measurements.

For continuous dependent variables, Student's t-test was used to detect the differences between the gender groups because the parametric test assumptions were satisfied. The Kruskal-Wallis test was used to detect the differences between the skeletal classes and variation groups because the parametric test assumptions were not satisfied. As significant differences were found in length between the variant groups, the Mann-Whitney $U$ test was used to make multiple comparisons with Bonferroni's correction. For the categorically dependent variables, Pearson ChiSquare or Fisher-Freeman Halton Exact test was used for testing the independence. The probability of a Type I error (alpha) was chosen as $5 \%$ in all tests. Statistical Analysis was performed using the Statistical Package for Social Sciences (SPSS for Windows, version 17.0, Chicago, IL, USA).
This study was approved by Başkent University Medical and Health Sciences Research Council and Ethics Committee (Project No: KA17 / 49).

\section{Results}

A moderate level of agreement was calculated between the two rater assessments for sella turcica variations. For all numeric variables, the correlations between the two rater measurements were detected to be strong.

In this study, 38 (40.4\%) of the lateral cephalometric radiographs were evaluated as the images of normal sella turcica. Irregularity in the posterior part of sella turcica was observed in $21(22.3 \%)$, pyramidal shape of dorsum sellae was observed in $13(13.8 \%)$, double contour of the floor was observed in 9 (9.6\%), sella turcica bridge was observed in $7(7.4 \%)$, and oblique anterior wall was observed in $6(6.4 \%)$ cases (Table 1).

There was a significant relationship between sella turcica variations and skeletal classes $(\mathrm{p}=0.017)$. Normal sella turcica was the most common (46.7\%) variant in patients who had skeletal class I malocclusions. This ratio was $30.3 \%$ and $45.2 \%$ in the skeletal Class II and III patients respectively, with the most common variant being the normal sella turcica in these patients. $24.2 \%$ of the Class II patients were had irregularity in the posterior part of sella turcica. The least common variation in patients with Class II malocclusion was the double contour of the floor (6.1\%). In patients with Class III malocclusion, the second most common variant after normal sella turcica was an irregularity in the posterior part of sella turcica (29\%). The double contour of the floor and sella turcica bridge variants were not found in this group (Table 1). There was a significant relationship between sella turcica variations and gender $(\mathrm{p}=0.358)$ (Table 2).

In the sella turcica measurements of 94 cases, the mean length was $9.74 \mathrm{~mm} \pm 2.09$, the mean depth was $8.03 \pm 1.34$, and the median diameter was $11.65 \mathrm{~mm}(7.4-16.7)$. No 
Table 2

Number of patients by sella turcica variations and genders.

\begin{tabular}{lccc|c}
\hline Sella turcica variants & Female & Male & Total & p \\
\hline Normal & $21(45.7 \%)$ & $17(35.4 \%)$ & $38(100 \%)$ & $6(6.4 \%)$ \\
Oblique anterior wall & $1(2.2 \%)$ & $5(10.4 \%)$ & $9(9.6 \%)$ & $7(7.4 \%)$ \\
Double contour of the floor & $4(8.7 \%)$ & $5(10.4 \%)$ & $21(22.3 \%)$ & $0.358^{*}$ \\
Sella turcica bridge & $4(8.7 \%)$ & $3(6.3 \%)$ & $13(13.8 \%)$ & \\
Irregularity in the posterior part & $12(26.1 \%)$ & $9(18.8 \%)$ & $9(18.8 \%)$ & $94(100 \%)$ \\
Pyramidal shape of dorsum sellae & $4(8.7 \%)$ & $48(100 \%)$ & \\
\hline Total & $46(100 \%)$ & & \\
\hline
\end{tabular}

*Fisher-Freeman-Halton exact test

statistically significant difference was found between males and females for the length, depth, and diameter $(\mathrm{p}=0.069$; $\mathrm{p}=0.280 ; \mathrm{p}=0.951$, respectively) (Table 3).

There was a statistically significant difference between the sella turcica variants in terms of length $(\mathrm{p}=0.023)$. Among the variants, the highest values in length were observed for the oblique anterior wall variant. In order to determine which individual variant groups resulted in these differences, Mann-Whitney $\mathrm{U}$ test was used for multiple comparisons with Bonferroni's correction. These tests demonstrated the significant differences between first, the oblique anterior wall and double contour of the floor variants; and secondly between the double contour of the floor and pyramidal shape of dorsum sellae variants. On the contrary, there were no statistically significant differences between the sella turcica variations in terms of depth and diameter $(\mathrm{p}=0.598 ; \mathrm{p}=0.179$, respectively) (Table 4).

The differences between the skeletal classification types and the length, depth, and diameter values of the sella turcica were not statistically significant $(\mathrm{p}=0.060$, $\mathrm{p}=0.492$, and $\mathrm{p}=0.077$, respectively) (Table 5).
Table 3

Length, depth and diameter measurements of sella turcica according to gender.

\begin{tabular}{lccc}
\hline & $\begin{array}{c}\text { Female } \\
(\text { Mean } \pm \text { SD })\end{array}$ & $\begin{array}{c}\text { Male } \\
(\text { Mean } \pm \text { SD })\end{array}$ & p \\
\hline Length $(\mathrm{mm})$ & $9.34 \pm 1.75$ & $10.12 \pm 2.33$ & $0.069^{*}$ \\
Depth $(\mathrm{mm})$ & $7.88 \pm 1.3$ & $8.18 \pm 1.38$ & $0.280^{*}$ \\
Diameter $(\mathrm{mm})$ & $11.65 \pm 1.35$ & $11.63 \pm 1.9$ & $0.951^{*}$ \\
\hline
\end{tabular}

*Student's t test. SD: standart deviation.

\section{Discussion}

In our study, the linear measurements and morphological structures of the sellae turcica were examined and compared in patients with different skeletal classes. We observed normal sella turcica in $40.4 \%$ of the patients. Valizadeh et al. ${ }^{[7]}$ found normal sella turcica in $24.4 \%$ of their patients which was lower than our study. $\mathrm{Al}$ Kofide $^{[14]}$ found normal sella at a percentage of $67 \%$ which was higher than our study. The difference in percentages may be due to varying ethnic origins.

The sella turcica bridge is one of the variants and is defined as the ossification in dura mater between the

Table 4

Descriptive statistics for length, depth, and diameter in sella turcica variations.

\begin{tabular}{lccc}
\hline Sella turcica variants & $\begin{array}{c}\text { Length }(\mathbf{m m}) \\
\text { Median }(\mathbf{m i n}-\mathbf{m a x})\end{array}$ & $\begin{array}{c}\text { Depth (mm) } \\
\text { Median (min-max) }\end{array}$ & $\begin{array}{c}\text { Diameter (mm) } \\
\text { Median (min-max) }\end{array}$ \\
\hline Normal sella turcica & $9.45(6.30-15.4)$ & $8.1(4.7-11.7)$ & $11.9(8.9-16.2)$ \\
Oblique anterior wall & $10.9(9.7-16.4)$ & $7.35(4.8-10.2)$ & $12.7(11-16.7)$ \\
Double contour of the floor & $8.9(5.5-10.3)$ & $7.7(5.7-9.8)$ & $10.9(8.8-12.8)$ \\
Sella turcica bridge & $8.7(7.7-11.6)$ & $8.7(5.6-9.9)$ & $11.8(7.4-13)$ \\
Irregularity in the posterior part of sella turcica & $9(6-13.5)$ & $7.4(6.4-10.8)$ & $11.1(9.5-14.4)$ \\
Pyramidal shape of dorsum sellae & $10.4(7.4-15.1)$ & $8(5.8-9.6)$ & $11.3(9.2-13.2)$ \\
\hline$p$ & $0.023^{*}$ & $0.598^{*}$ & $0.179^{*}$ \\
\hline
\end{tabular}

*Kruskal-Wallis test. 
anterior and posterior clinoid processes. This malformation can also be seen in healthy individuals. ${ }^{[15]}$ In the present study, the sella turcica bridge was seen in $3.2 \%$ of the Class I patients; in $4.3 \%$ of the Class II patients, and at a $7.4 \%$ frequency in total. But this variant was not observed in the Class III patients. Sella turcica bridge rate was found to be close to the rate found in our study: $5.5 \%$ by Axelson et al. ${ }^{[1]]} 23.3 \%$ by Valizadeh et al., ${ }^{[7]}$ and $1.1 \%$ by Al Kofide et al. ${ }^{[14]}$

Meyer-Marcotty et al. ${ }^{[17]}$ found the sella turcica bridge more commonly in Class II patients (16.8\%) compared to Class I patients (9.4\%). Similarly, in their study involving adult women, Marşan and Öztaş ${ }^{[18]}$ found sella turcica bridge more commonly in Class III patients $(18 \%)$. In our study, this variation was not seen in Class III patients. These different results in the literature may be due to the number of included subjects and their existing malformations. The sella turcica bridge is also associated with the deviation developing during the dentation. ${ }^{[17,18]}$ Studies in pediatric populations demonstrated an association between this malformation and the craniofacial deviations, and also reported that the treatment of malocclusions was more complex in these patients. ${ }^{[2,15]}$

Similar to the findings of $\mathrm{Al}$ Kofide et al., ${ }^{[14]}$ the differences in length, depth, and diameter were not statistically significant between the males and females in our study. In our study, there was no statistically significant difference in length, depth, and diameter measurements among patients with Class I, II, and III malocclusions. In contrast, Valizadeh et al. ${ }^{[7]}$ found higher values in terms of length in Class III cases compared to those values observed in Class I and II patients. Al Kofide ${ }^{[14]}$ also found a statistically significant difference in diameter measurements between Class II and Class III patients.

In a study by Canigur Bavbek and Dincer ${ }^{[12]}$ lower rates of normal sella morphology were observed in diabetic patients compared to healthy individuals. Sella turcica enlarges with increased age. However, in our study, patients with endocrine disorders were excluded and age limits were defined for the study patients to evaluate the measurements.

Rai et al. ${ }^{[19]}$ analyzed the shape and size of sella turci$\mathrm{ca}$, and four groups were described according to the shape of the hypophyseal fossa and posterior clinoid process, which was a different methodology compared to our study. Then, the sizes were examined according to the gender and age. All values in women were observed to be higher than the values measured in males. However, in our study, there was no statistically significant difference according to gender.
Table 5

Descriptive statistics of length, depth, and diameter measurements of sella turcica in Classes I, II, III malocclusions.

\begin{tabular}{lcccc}
\hline $\begin{array}{l}\text { Skeletal } \\
\text { classes }\end{array}$ & $\begin{array}{c}\text { Class I } \\
\text { Median } \\
(\text { min-max })\end{array}$ & $\begin{array}{c}\text { Class II } \\
\text { Median } \\
(\text { min-max })\end{array}$ & $\begin{array}{c}\text { Class III } \\
\text { Median } \\
(\text { min-max })\end{array}$ & $\mathbf{p}$ \\
\hline Length (mm) & $10(5.5-13.3)$ & $8.3(4.7-11.7)$ & $12.25(8.8-15.2)$ & $0.06^{*}$ \\
Depth (mm) & $8.9(6-12)$ & $7.7(4.8-9.9)$ & $11.1(7.4-15.1)$ & $0.492^{*}$ \\
Diameter (mm) & $10(6-16.4)$ & $7.9(6.3-10.8)$ & $11.8(9.1-16.7)$ & $0.077^{*}$ \\
\hline
\end{tabular}

*Kruskal-Wallis test.

Some congenital syndromes, such as Down syndrome, trisomy 21, myelomeningocele, Meckel-Gruber syndrome, anencephaly, trisomy 18, chondrodystrophy, hydrocephaly, Williams syndrome, and Seckel syndrome may affect the shape and size of sella turcica. Small sella turcica may result from a necrosed hypophysis due to infarction. Sella turcica may enlarge due to the enlargement of the hypophysis. An enlarged sella turcica may also be observed in empty sella syndrome, where the herniation of the subarachnoid space with cerebrospinal fluid occurs. ${ }^{[6,10,19]}$

Yasa et al. ${ }^{[4]}$ used cone beam computed tomography to examine the sella turcica morphology. Using a different classification system, they found that $69.5 \%$ of the cases had a circular morphology, $16.4 \%$ were flat, and $14 \%$ were oval in shape.

Due to their common embryological origins, the association between various dental anomalies and the sella turcica bridge variant has received the attention from the investigators. Ali et al. ${ }^{[16]}$ found a higher rate of sella turcica bridge in patients with buried canine teeth. In this study, sella turcica bridge is seen more commonly in Class II patients. The morphology and size of the anterior and posterior clinoid processes are important for vascular surgery and trans-sphenoidal endoscopic procedures. To decrease the risk of intraoperative complications, the anatomy of this region should be evaluated thoroughly. ${ }^{[8}$

\section{Conclusion}

Results of this study in regards to sella turcica variations and associated measurements will contribute to the normal reference standards which will be used by future studies on craniofacial malformations and syndromes. Furthermore, the results of the study are of importance in terms of raising the awareness of orthodontists to identify the sella turcica variations in lateral cephalometric radiographs used in the diagnosis and treatment planning, as these findings will allow considering the associated pathologies and patient referrals accordingly. 


\section{References}

1. Arıncı K, Elhan A. Anatomi. Cilt 1. Ankara: Güneş Kitabevi; 2001. p. 35-6.

2. Kucia A, Jankowski T, Siewniak M, Janiszewska-Olszowska J, Grocholewicz K, Szych Z, Wilk G. Sella turcica anomalies on lateral cephalometric radiographs of Polish children. Dentomaxillofac Radiol 2014;43:20140165.

3. Sathyanarayana HP, Kailasam V, Chitharanjan AB. Sella turcica - its importance in orthodontics and craniofacial morphology. Dent Res J (Isfahan) 2013;10:571-5.

4. Yasa Y, Ocak A, Bayrakdar IS, Duman SB, Gumussoy I. Morphometric analysis of sella turcica using cone beam computed tomography. J Craniofac Surg 2017;28:70-4.

5. Taşçıŏlu B. Sellar bölge anatomisi. Türk Nöroşirürji Dergisi 2006; 16:75-6.

6. Tekiner H, Acer N, Kelestimur F. Sella turcica: an anatomical, endocrinological, and historical perspective. Pituitary 2015;18:5758.

7. Valizadeh S, Shahbeig S, Mohseni S, Azimi F, Bakhshandeh H. Correlation of shape and size of sella turcica with the type of facial skeletal class in an Iranian group. Iran J Radiol 2015;12: e16059.

8. Cheng Y, Chen Y, Zhou Z, Zhu J, Feng Y, Zhao G. Anatomical study of posterior clinoid process (PCP) and its clinical meanings. J Craniofac Surg 2015;26:537-40.

9. Brock-Jacobsen MT, Pallisgaard C, Kjaer I. The morphology of the sella turcica in monozygotic twins. Twin Res Hum Genet 2009;12: 598-604.
10. Kjær I. Sella turcica morphology and the pituitary gland-a new contribution to craniofacial diagnostics based on histology and neuroradiology. Eur J Orthod 2015;37:28-36.

11. Axelsson S, Storhaug K, Kjaer I. Post-natal size and morphology of the sella turcica. Longitudinal cephalometric standards for Norwegians between 6 and 21 years of age. Eur J Orthod 2004;26: 597-604.

12. Canigur Bavbek N, Dincer M. Dimensions and morphologic variations of sella turcica in type 1 diabetic patients. Am J Orthod Dentofacial Orthop 2014;145:179-87.

13. Korayem M, Alkofide E. Size and shape of the sella turcica in subjects with Down syndrome. Orthod Craniofac Res 2015;8:43-50.

14. Alkofide EA. The shape and size of the sella turcica in skeletal Class I, Class II, Class III Saudi subjects. Eur J Orthod 2007;29:457-63.

15. Brahmbhatt RJ, Bansal M, Mehta C, Chauhan KB. Prevalence and dimensions of complete sella turcica bridges and its clinical significance. Indian J Surg 2015;77:299-301.

16. Ali B, Shaikh A, Fida M. Association between sella turcica bridging and palatal canine impaction. Am J Orthod Dentofacial Orthop 2014; 146:437-41.

17. Meyer-Marcotty P, Reuther T, Stellzig-Eisenhauer A. Bridging of sella turcica in skeletal Class III subjects. Eur J Orthod 2010;32:259-63.

18. Marşan G, Öztaş E. Incidence of bridging and dimensions of sella turcica in Class I and III Turkish adult female patients. World J Orthod 2009;10:99-103.

19. Rai AR, Rai R, Pc V, Rai R, Vadgaonkar R, Tonse M. A cephalometric analysis on magnitudes and shape of sella turcica. J Craniofac Surg 2016;27:1317-20.

Correspondence to: Hale Öktem, MD

Department of Anatomy, Faculty of Medicine,

Başkent University, Ankara, Turkey

Phone: +90 3122466689

e-mail: haleoktem@gmail.com

Conflict of interest statement: No conflicts declared.

This is an open access article distributed under the terms of the Creative Commons Attribution-NonCommercial-NoDerivs 3.0 Unported (CC BY-NCND3.0) Licence (http://creativecommons.org/licenses/by-nc-nd/3.0/) which permits unrestricted noncommercial use, distribution, and reproduction in any medium, provided the original work is properly cited. Please cite this article as: Öktem H, Tuncer Nİ, Şençelikel T, Bağcı Zİ, Cesaretli S, Arslan A, Gürsel IT, Değirmenci B. Sella turcica variations in lateral cephalometric radiographs and their association with malocclusions. Anatomy 2018;12(1): 13-19. 